\title{
Hypoglossal nerve palsy complicating a case of infectious mononucleosis
}

\author{
J. R. SIBERT \\ M.A., M.B., M.R.C.P., D.C.H., D.Obst.R.C.O.G. \\ Radcliffe Infirmary, Oxford
}

\section{Summary}

A case of infectious mononucleosis complicated by the rare neurological complication of left isolated hypoglossal nerve palsy is described. The literature on cranial nerve palsies in infectious mononucleosis is briefly reviewed.

\section{Case report}

R.G., a 17-year-old management trainee, was admitted to the Radcliffe Infirmary with a 1 week history of sore throat, headache loss of appetite, shivers, nausea and malaise. He had been given a course of penicillin $\mathrm{V}$ on the second day of his illness by his general practitioner without improvement.

On examination he looked ill and had a temperature of $38 \cdot 2^{\circ} \mathrm{C}$. There was generalized lymphadenopathy in the cervical region. There were exudates on inflamed tonsils. The spleen and liver were not palpable. There was no abnormality in the central nervous system, and in particular the cranial nerves were normal with tongue protruding centrally.

Investigations showed a haemoglobin of $15.2 \mathrm{~g} /$ $100 \mathrm{ml}$, WBC 11900 with $70 \%$ atypical mononuclears compatible with glandular fever. Monospot differential slide test was positive. Paul-Bunnel was positive in titres of saline $1: 10240$, guinea-pig kidney $1: 5120$ and ox cells $1: 640$. Antibody to EB virus was present in the serum. Throat swab grew no recognized pathogens. SMA biochemical profile revealed a raised LDH and SGOT at $600 \mathrm{mIU}$ and $750 \mathrm{mIU}$ respectively. Alkaline phosphates was $16 \mathrm{KA}$ units. Bilirubin was $0.6 \mathrm{mg} / 100 \mathrm{ml}$.

A diagnosis of infectious mononucleosis was made and he was put on a course of steroids starting with prednisolone $10 \mathrm{mg}$ q.d.s. and reducing to nil in 8 days.

On this regimen the fever came down to normal within 3 days and he felt better. However, on the fifth day of his hospital admission he complained of difficulty in using his tongue. On examination the tongue deviated to the left on protrusion. There was left-sided muscle wasting and fasiculation. Full neurological examination revealed no other abnormality. There was no nystagmus or intention tremor, and no other lesion was found in the cranial nerves. Speech was normal.

Further investigations showed a CSF at normal pressure with a cell count of four WBC (two lymphocytes and two polymorphs) protein $20 \mathrm{mg} /$ $100 \mathrm{ml}$ and sugar normal. WR was negative in the serum.

His general condition improved at about the same time as his hypoglossal palsy was noted. He was discharged 10 days after his admission. When seen 6 months after his illness his tongue was still wasted and protruded to the left, but he had no complaints.

\section{Discussion}

Neurological involvement in infectious mononucleosis is uncommon. Evans, (1963) reviewing the British and American literature, found only seventyeight cases, although he did not include cases of lymphocytic meningitis. Rugg-Gunn (1954) described three cases in a series of 412, however Gautier Smith (1965) found eight cases in 109. Gautier Smith (1965) divided the neurological complications into lymphocytic meningitis, encephalomyelitis, polyneuritis and mononeuritis. Of these, mononeuritis seems the least common. Most cranial nerves have been reported to have been involved either alone or in combination.

Oculomotor involvement has been described twice (Nellhaus, 1966; Evans, 1963), lateral rectus palsy once (Vaughan, Regan \& Terplan, 1946), and facial palsy three times (Cambier, Masson \& Plamfosse, 1963; Davidson \& Salter, 1964; Egan, 1960). Facial and trigeminal involvement together has been reported twice (Silverside \& Richardson, 1950; Taylor \& Parsons Smith, 1969), the latter case having nerve deafness in addition. The only case reported involving the lower cranial nerves is by Chatterjee (1960) who describes a patient with left-sided palatal, sternomastoid and hypoglossal weakness together with a bradycardia presumably associated with vagal involvement.

The relation between the time of onset of the general manifestations of infectious mononucleosis and the time of onset of the cranial nerve palsies 
varies greatly. With Nellhaus' case the neurological manifestations came on 20 days before the systemic ones, and with Chatterjee's case 24 days after. The interval between the onset of the sore throat and the detection of the hypoglassol palsy was 12 days in this case.

The pathological explanation for this neurological complication is presumably a local virus infection around the hypoglossal nerve nucleus. However, Bergin (1960), suggested that an 'allergic neurotaxitis' similar to that found in the encephalitis of measles and some other specific fevers might be responsible for some of the neurological manifestations of infectious mononucleosis.

\section{Acknowledgement}

I should like to thank Dr T. D. R. Hockaday for his advice and for his permission to publish the case.

\section{References}

BERGIN, J.D. (1960) Fatal encephalopathy in glandular fever. Journal of Neurology, Neurosurgery and Psychiatry, 23, 69. Cambier, J., Masson, M. \& Plamfossé, M.C. (1963) Diplegie faciale, complication evolutive d'une mononucleose infectieuse aiguie. La Presse Medicale, 71, 410.

Chatterjee, A. K. (1961) An unusual neurological complication of infectious mononucleosis. British Journal of Clinical Practice, 15, 595.

Davidson, R.J.L. \& SAlTER, R.H. (1964) Infectious mononucelosis presenting with facial diplegia. British Medical Journal, 1, 954.

EgAN, R.W. (1960) Facial diplegia in infectious mononucleosis in the absence of Landry-Guillain-Barre Syndrome. New England Journal of Medicine, 262, 1178.

Evans, J.G. (1963) Neurological complications of glandular fever. Ulster Medical Journal, 32, 31.

Gautier Smith, P.C. (1965) Neurological complications of glandular fever. Brain, 88, 323.

Nellhaus, G. (1966) Isolated oculomotor nerve palsy in infectious mononucleosis. Neurology, 15, 221.

RugG-GunN, M.A. (1954) Infectious mononucleosis. A review of the condition as seen in the Royal Navy. Proceedings of the Royal Society of Medicine, 47, 759.

Silverside, J.L. \& Richardson, J.C. (1950) Neurological complications of infectious mononucleosis. Canadian Medical Association Journal, 63, 138.

TAYlor, L. \& Parsons-Smith, G. (1969) Infectious mononucleosis, deafness and facial paralysis. Journal of Laryngology and Otology, 83, 613.

VAughaN, S.L., RegaN, J.S., \& TARPlaN, P.K. (1946) Infectious mononucleosis complicated by spontaneous rupture of the spleen and central nervous system involvement. Blood, 1, 334.

\title{
Successful resection of mycotic aneurysm of the superior mesenteric artery
}

\author{
C. R. Kumana \\ B.Sc., M.B., B.S., M.R.C.P.
}

R. J. E. FOLEY

M.B., B.S., F.R.C.S.

Whipps Cross Hospital, Leytonstone, London, E.11

\begin{abstract}
Summary
A patient with subacute bacterial endocarditis is presented in whom an intra-abdominal mycotic aneurysm was diagnosed prior to the development of cardiac signs. The patient was successfully treated for his endocarditis and the aneurysm which proved to be arising in a branch of the superior mesenteric artery was resected.
\end{abstract}

INTEREST in mycotic aneurysms was mainly academic until the advent of antibiotics, as until then the underlying disease was usually fatal. The superior mesenteric artery (with its branches) is rarely the site of an aneurysm, nonetheless, it constitutes a territory of predilection for mycotic aneurysms. The management of such aneurysms is complicated because the superior mesenteric artery is an end artery and the viability of the bowel it supplies must be maintained.

\section{Case report}

A 45-year-old man was admitted as an emergency with bizarre neurological symptoms.

He gave a 6 months' history of increasing malaise, aches and pains, anorexia and weight loss. This culminated in him giving up work 2 months prior to admission to this hospital, at which time he attended another hospital for his symptoms.

He presented at Whipps Cross Hospital with increasing drowsiness, associated with pain and stiffness of the left shoulder. He had been unable to swallow and would occasionally grimace and become incoherent. There was no past history of cardiac disease, but for the past 8 months he had been attending his dentist. 